\title{
Sustaining This Massive Shade
}

1.

Of all that is left to occur

when nothing moves

but beneath my skull

a dog stretching tremulous forelegs.

Cicadas drone in every tendon

while the wind offers nothing

to keep insects from the skin.

And still he returns

like a new leaf reviving.

In sum, what nightfall has in store.

I keep four calendars he said.

Beneath one moon

I am jealous.

Of all that touches him,

the rain that doesn't fall

and the woman that lies next to him.

In this age of hands,

where are mine.

I am intact and I don't care.

My hands in the garden.

Corn bleached

and malformed by drought

beneath the sick of blue.

2.

I have the white-blue eyes of my ancestors he said, their narrow skull and their clumsiness in fighting.

Fighting to keep my hand from his belly where sleeps a double sex.

Struggling not to touch 
the small bones held in by sandals,

I take note of his every step.

Given confidence

and confiding in the agave.

The cactus mourns the memory of feeling

and mysterious delicacies seduce me.

That this night would give up

one breath

to stir the downy hairs on his golden legs.

The skin that aches

for want of feather.

3.

How I move between rooms,

the cattle of longing

and think only of that curve

at the base of his skull.

The cowlick clipped

to a choirboy's mean halo.

I am happy he said.

I am jealous.

Of the planets

that seduce him with greater success

and the moon that lights his pale arm

when he rises in the night.

Walk through the night, gently moving that thigh, that second thigh and that left leg. 